Home

Subject List

Alphabetical List

Help

FAQ

Highlights

Deutsche Version

Quick Search

Advanced Search $>>$

\section{Single Articles}

View Shopping Cart

\section{LogIn}

Username

Password

Log In

Register Now

Forgot your password?
Planta Med 2012; 78

DOI : $10.1055 / \mathrm{s}-0032-1307556$

\section{Bioassay-Directed Isolation and Identification of Phytotoxic Terpenoids from Horseweed (Conyza Canadensis)}

\section{SCN Queiroz ${ }^{1}$, CL Cantrell $^{2}$, so Duke ${ }^{2}$, v Nandula $^{3}$, RM Moraes ${ }^{4}$,} AL Cerdeira 1

1 Embrapa/Environment, Research Division of Brazilian Department of Agriculture, C.P. 69, Jaguariúna, SP, 13820-000, Brazil

2 USDA-ARS, National Products Utilization Research Unit (NPURU), University, Oxford, MS, 38677, USA

3 USDA-ARS, Crop Production Systems Research Unit 141 Experiment Station Road, PO Box 350, Stoneville, MS 38776, USA

4 Biological Field Station. University of Mississippi, 15 County Road 2078 Abbeville, MS 38601, USA

Horseweed [Conyza canadensis (L.) Cronquist, syn. Erigeron canadensis L.], Asteraceae, is a common weed with known allelopathic effects but few studies on the isolation and identification of the phytotoxic compounds have been reported [1]. C. canadensis infests orchards, vineyards, field crops such as corn, soybean and cotton, particularly in herbicide-resistant crops where conservation tillage or no-till systems are used. The objective of this study was to identify the phytotoxic compounds present by systematically performing bioassay-directed isolation and subsequent identification of the bioactive constituents according to Dayan et al. [2]. No significant phytotoxic activity against Lactuca sativa or Agrostis stolonifera was detected in methanol, or water extracts when tested at $1.0 \mathrm{mg} \cdot \mathrm{mL}^{-1}$; however, the dichloromethane extract was active. Further fractionation using liquid-liquid partitioning with hexane, chloroform, ethyl acetate and water was performed with the DCM extract. The most active extract (chloroform) was subjected to preparative HPLC and the fractions were tested again. The active compounds were isolated and identified by GC-MS and ${ }^{1} \mathrm{H}$ - and ${ }^{13} \mathrm{C}$-NMR. The isolated compounds (Figure 1 ) were identified as $(2 Z, 8 Z)$-matricaria acid methyl ester, $(4 Z, 8 Z)$-matricarialactone and (4Z)-lachnophyllumlactone. Compound 3 shows similar activity as compound 2 .

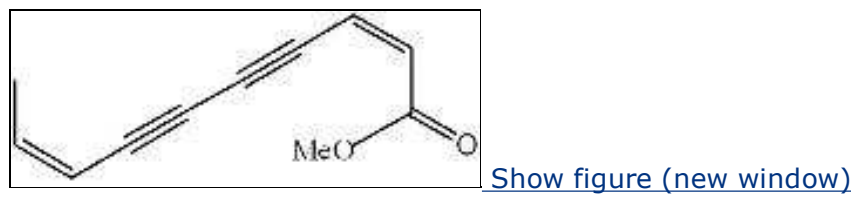

1

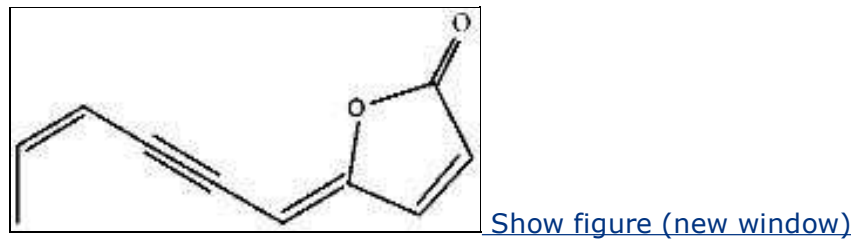

2

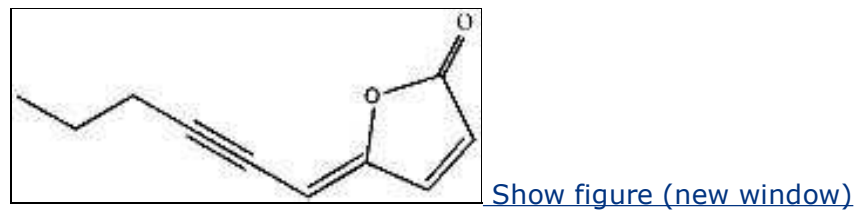

3Fig.1: Isolated compounds: 1) (2Z,8Z)-matricaria acid methyl ester, 2) $(4 Z, 8 Z)$-matricarialactone and 3) (4Z)-lachnophyllumlactone.

Acknowledgements: The authors thank Solomon Green III, Robert Johnson, and Amber Callahan for technical assistance at NPURU, USDA-ARS.

References: [1] Gao XX, Li M, et al. (2009) Allelopath J 23: 287-296. [2]

Dayan FE, Romagni JG, et al. (2000)J Chem Ecol 26: 2079-2094.

\section{Content}

Abstract Only (Why?)

Table of Contents of this Issue

Other Issues:

\section{2}

Issue

\section{Congress Abstracts}

11th Annual Oxford

International

Conference on the

Science of Botanicals

(ICBS) Abstracts

List of Authors

About This Journal

Aims and Scope

Editorial Information

Instructions for Authors

Submit a Manuscript

Subscribe Now

\section{Service}

Sample Issue (01/2012)

Recommend this Article Recommend this Journal

\section{German National}

License

Download

Bibliographical Data

\section{Bookmark Article}

Connotea

Delicious

CiteULike 